\title{
Meta-analysis of thyroidectomy with ultrasonic dissector versus conventional clamp and tie
}

\author{
Roberto Cirocchi ${ }^{*}$, Fabio D'Ajello ${ }^{2}$, Stefano Trastulli ${ }^{1}$, Alberto Santoro ${ }^{3}$, Giorgio Di Rocco ${ }^{3}$, Domenico Vendettuoli ${ }^{3}$, \\ Fabio Rondelli ${ }^{1}$, Domenico Giannotti ${ }^{3}$, Alessandro Sanguinetti ${ }^{2}$, Liliana Minelli ${ }^{4}$, Adriano Redler ${ }^{3}$, Antonio Basoli ${ }^{5}$, \\ Nicola Avenia ${ }^{2}$
}

\begin{abstract}
Background: We conducted a systematic review to evaluate the role of Ultrasonic dissector (UAS) versus conventional clamp and tie in thyroidectomy.

Materials and methods: We searched for all published RCT in into electronic databases. To be included in the analysis, the studies had to compare thyroidectomy with UAS versus conventional vessel ligation and tight (conventional technique $=\mathrm{CT}$ ). The following outcomes were used to compare the total thyroidectomy group with UAS versus CT group: operative duration, operative blood loss, overall drainage volume during the first 24 hours, transiet laryngeal nerve palsy, permanent laryngeal nerve palsy, transiet hypocalcaemia and permanent hypocalcaemia.

Results: There are currently 7 RCT on this issue to compare thyroidectomy with UAS versus CT. From the analysis of these studies it was possible to confront 608 cases: 303 undergoing to thyroidectomy with UAS versus 305 that were treated with CT. Actually, it was shown a relevant advantage of cost-effectiveness in patients treated with UAS; there is a statistically significant reduction of the operative duration (weighted mean difference [WMD], -18.74 minutes; 95\% confidence interval [CI], (-26.97 to -10.52 minutes) $(P=0.00001)$, intraoperative blood loss (WMD, $-60.10 \mathrm{~mL} ; 95 \% \mathrm{Cl}$, -117.04 to $3.16 \mathrm{~mL})(\mathrm{P}=0.04)$ and overall drainage volume (WMD, -35.30 mL; 95\% Cl, -49.24 to $21.36 \mathrm{~mL})(\mathrm{P}=0.00001)$ in the patients underwent thyroidectomy with UAS. Although the analysis showed that the patients who were treated with USA presented more favourable results in incidence of post-operative complications (transient laryngeal nerve palsy: $P=0.11$; permanent laryngeal nerve palsy: not estimable; transient hypocalcaemia: $P=0.24$; permanent hypocalcaemia: $P=0.45$ ), these data didn't present statistical relevance.

Conclusion: This meta-analysis shown a relevant advantage only in terms of cost-effectiveness in patients treated with UAS; it is subsequent to statistically significant reduction of operation duration, intraoperative blood loss and of overall drainage volume during the first 24 hours. Although the analysis showed that the patients who were treated with UAS presented more favourable results in incidence of post-operative complications (transiet laryngeal nerve palsy; transiet hypocalcaemia and permanent hypocalcaemia), these data didn't present statistical relevance.
\end{abstract}

\section{Introduction}

The basis for the thyroid surgery was founded by Theodor Billroth and Theodor Kocher, between 1873 and 1893, that standardized and precise anatomical dissection with preliminary ligation of the two principal

\footnotetext{
*Correspondence: cirocchiroberto@yahoo.it

'General and Emergency Surgical Unit. Department of Surgical Sciences,

Radiology and Dentistry. University of Perugia, Perugia, Italy

Full list of author information is available at the end of the article
}

arteries of the gland on each side, followed by excision of the gland [1].

During the last ten years MIVAT (Minimally invasive video assisted throidectomy) was standardized by Miccoli in 1999 [2], and various devices were introduced in order to do a safe section and haemostasis of thyroidal vessels (LigaSure and Ultrasonic dissector) [3]. The Ultracision dissector (UAS) (First generation
C Biomed Central 
"Harmonic scalpel"; Johnson \& Johnson ${ }^{\circledR}$ ) is a device that uses vibration at $55,5 \mathrm{KHz}$ simultaneously cut and coagulate tissue. The UAS works at lower temperature (ranging from $50^{\circ}$ to $100^{\circ} \mathrm{C}$ ) than electrosurgical device.

The aim of this systematic review is to evaluate the actual role of UAS versus conventional clamp and tie (CT) in total thyroidectomy.

\section{Methods of metanalysis}

\section{Search methods for identification of studies}

We planned to search for published Randomized Controlled Trials (RCTs) and Controlled Clinical Trials (CCTs), without language restrictions, using the following electronic databases:

- Cochrane Central Register of Controlled Trials (January 2010);

- MEDLINE (1966 to January 2010);

- EMBASE (1980 to January 2010);

- Science Citation Index (1981 to January 2010);

- ISI Proceedings (1990 to January 2010);

- Zetoc (searched January 2010);

- CINAHL (1982 to January 2010);

- Clinicaltrials.gov (searched January 2010).

The literature searches were carried out using the following medical subject headings $(\mathrm{MeSH})$ and free text words: "thyroidectomy"; "Harmonic scalpel", "Ultrasonic dissector". We also checked the reference lists of all studies identified.

\section{Data Extraction}

Two authors (RC, FD) assessed titles or abstracts of 56 all the studies identified by the initial search and excluded clearly non-relevant studies. They obtained the full text of all potentially relevant studies and also those with unclear methodology. These studies were assessed by the two authors as to whether they met the inclusion criteria for this review. One disagreements on inclusion were resolved by discussing and, if necessary, by involving an independent third author (ST).

\section{Inclusion Criteria}

To be included in the analysis, the studies had to compare total thyroidectomy with UAS versus CT.

\section{Exclusion Criteria}

Studies were excluded from the meta-analysis if the outcomes of interest were not reported for the two techniques or there was a considerable overlap between authors, centres or patient cohorts evaluated. More extended surgical procedure adding central neck dissection (level 6 lymphadenectomy) were excluded.

\section{Outcomes of Interest}

The following outcomes were used to compare the total thyroidectomy group with UAS versus CT group:

- Operative duration (minutes).

- Operative blood loss (mL).

- Overall drainage volume $(\mathrm{mL})$ during the first 24 hours.

- Transiet laryngeal nerve palsy (no. of patients).

- Permanent laryngeal nerve palsy (no. of patients).

- Transiet hypocalcaemia (no. of patients).

- Permanent hypocalcaemia (no. of patients).

\section{Methodological quality}

RC, DF and ST assessed the methodological quality of each trial independently.

\section{Measures of treatment effect}

Data were analyzed for odds ratio (OR) in the case of dichotomous variables, and weighted mean difference (WMD) for continuous variables. Ninety five \% confidence intervals $(95 \% \mathrm{CI})$ were calculated for these measures of effect. Intention-to-treat analyses were performed extracting the number of patients originally allocated to each treatment group irrespective of compliance. The Mantel-Haenszel method was used for the meta-analysis. Results were presented on a forest plot graph.

\section{Assessment of heterogeneity}

The Chi2 test was employed for heterogeneity assessment. The outcomes were measured with continuous scales, while data of treatment effects were analysed with mean difference. If different trials used different scales, we standardized and combined the results (i.e. standardized mean difference).

\section{Statistical Analysis}

The data analysis was performed using the meta-analysis software Review Manager (RevMan) v 5.0.17 (Copenhagen: The Nordic Cochrane Centre, The Cochrane Collaboration, 2008).

\section{Results for the Meta-Analysis Eligible Studies}

There are currently $8 \mathrm{RCT}$ on this issue to compare thyroidectomy with UAS (First generation "Harmonic scalpel"; Johnson \& Johnson ${ }^{\circledR}$ ) versus CT [4-11], a study is excluded for the impossibility to distinguish lobectomy from total thyroidectomy [11].

From the analysis of 7 studies it was possible to confront 608 cases divided into two groups [4-10] (Table 1): 


\section{Table 1 RCT included}

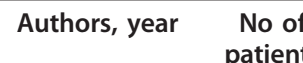

Age, Mean (SD), y

Pathological Operative Duration, Mean Operative Blood Loss

$\begin{array}{ll}\text { diagnosis of } & \text { (SD), } \mathrm{min}\end{array}$

Mean (SD), $\mathrm{ml}$

Length of Hospital No. of Patients with

No. of Patients Lesions, B/M Stay, Mean (SD), d Nerve plasy

Transiet Permanent Transiet Permanent

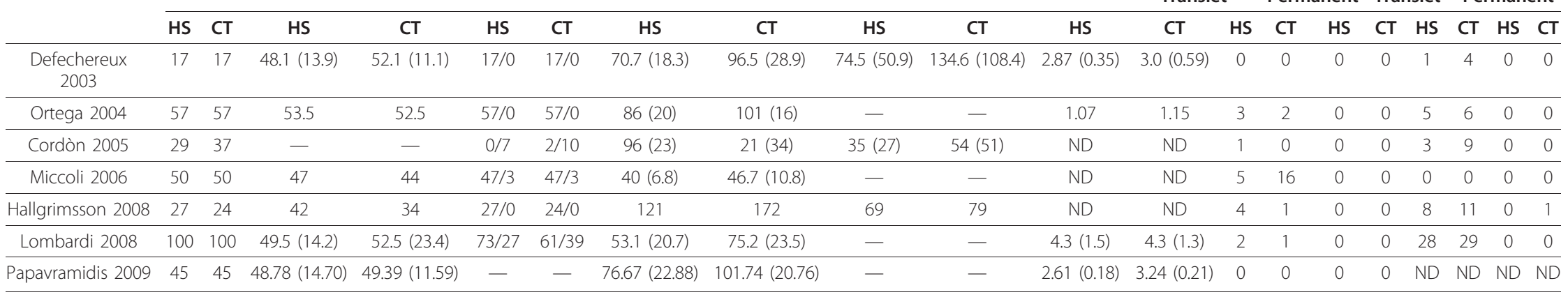


303 undergoing to total thyroidectomy with UAS versus 305 that were treated with CT.

\section{Results}

The operative time (WMD $=-18.74$ minutes; 95\% CI -26.97 to -10.52 minutes) was statistically relevant lower in the total thyroidectomy with UAS group ( $p=$ 0.00001) (Figure 1).

The intraoperative blood loss is only mentioned in one included trial $(\mathrm{WMD}=-60.10 \mathrm{~mL} ; 95 \% \mathrm{CI}-117.04$ to $3.16 \mathrm{~mL}$ ) was lower in the total thyroidectomy with UAS group ( $p=0.04)$ (Figure 2).

The overall drainage volume in one included trial $($ WMD $=-35.30 \mathrm{~mL} ; 95 \% \mathrm{CI}-49.24$ to $21.36 \mathrm{~mL}$ ) was significant lower in the total thyroidectomy with UAS group ( $p=0.00001)$ (Figure 3 ).

The incidence of transient laryngeal nerve palsy $(\mathrm{OR}=$ 2.51 no. of patients; $95 \%$ CI 0.81 to 7.78 no. of patients) was fewer in the total thyroidectomy with UAS group ( $p=$ 0.11) (Figure 4), but not confer any statistically significant advantage over CT; the incidence of permanent laryngeal nerve palsy was similar in the two groups (Figure 5).

There aren't relevant differences in the incidence of transient $(\mathrm{OR}=0.76$ no. of patients; $95 \%$ CI 0.48 to 1.21 no. of patients) $(p=0.24)$ (Figure 6) and permanent hypocalcaemia $(\mathrm{OR}=0.28$ no. of patients; $95 \%$ CI 0.01 to 7.33 no. of patients) $(p=0.45)$ was similar in the two groups (Figure 7).

\section{Discussion}

The ultrasonic dissector, although more costly, has gained wide acceptance because it may reduce intraoperative bleeding and operative duration. Reported benefits, however, were based on some RCTs and CCTs and conclusive evidence supporting either technique is lacking.

We conducted a systematic review and meta-analysis to compare the surgical effectiveness of ultrasonic vs clamp and tie in total thyroidectomy in patients with thyroid benign and/or malignant pathologies.

From our systematic review and meta-analysis the main advantages of UAS are shorter operative duration $(p=0,00001)$, lower intraoperative blood loss $(p=0,04)$ and lower overall drainage volume $(p=0,00001)$.

The significant advantage of this device is the simultaneously coagulating/dissecting functions, and subsequent timing reduction necessary for conventional clamp-andtie technique. This advantage was evidenced by Yao and coll. in their systematic review and meta-analysis on usage of Ligasure in total thyroidectomy [12] (WMD = -18.74 minutes in patients treated with con Ultrasonic dissector versus-20.32 minutes in patients treated with LigaSure). The reduction of operative time has the advantage to reduce significantly the costs of utilization of operating room.

The cut and coagulation functions permit also to reduce lymphorrea depending on ligations and sections, so the opportunity of anticipated demission and subsequent reduction of costs of permanence in the Hospital.

The utilization of Ultracision permits a more accurate dissection and a statistically significant reduction of intraoperative blood loss compared to the patients treated with conventional vessel ligation in thyroidectomy, no presence of advantage in patients treated with Ligasure [12] (WMD $=-60.10 \mathrm{~mL}$ in patients treated with Ultrasonic dissectors, $p=0.02$, versus $-25.13 \mathrm{~mL}$ in patients treated with LigaSure, $p=0.26$ ).

The incidence of post-operative complications is similar in two groups (transient laryngeal nerve palsy: $p=$ 0.11 ; permanent laryngeal nerve palsy: not estimable; transient hypocalcaemia: $p=0.24$; permanent hypocalcaemia: $p=0.45$ ). In the patients treated with Ultrasonic dissector we have only a little reduction of complications; that can be attributed to the technical characteristics of UAS that reduce lateral thermal injury, approximately half that caused by bipolar systems.

\begin{tabular}{|c|c|c|c|c|c|c|c|c|c|c|c|}
\hline \multirow[b]{2}{*}{ Study or Subgroup } & \multicolumn{3}{|c|}{ UAS } & \multicolumn{3}{|c|}{ Corwentional technique } & \multirow[b]{2}{*}{ Weight } & \multirow{2}{*}{$\begin{array}{l}\text { Mean Difference } \\
\text { N. Random, } 95 \% \text { Cl }\end{array}$} & \multirow{2}{*}{\multicolumn{3}{|c|}{$\begin{array}{l}\text { Mean Difference } \\
\text { IV. Random, } 95 \% \mathrm{Cl}\end{array}$}} \\
\hline & Mean & $\mathrm{SD}$ & Total & Mean & SD & Total & & & & & \\
\hline Cordòn 2005 & 104 & 29 & 7 & 136 & 37 & 12 & $5.7 \%$ & $-32.00[-62.00,-2.00]$ & $\hookleftarrow$ & & \\
\hline Defechereu $\times 2003$ & 70.7 & 18.3 & 17 & 96.5 & 28.9 & 17 & $12.3 x$ & $-25.80[-42.06,-9.54]$ & & & \\
\hline Hallgrimsson 2008 & 121 & 0 & 27 & 172 & 0 & 24 & & Not estimable & & & \\
\hline Lomb ardi 2008 & 53.1 & 20.7 & 100 & 75.2 & 23.5 & 100 & $20.8 \%$ & $-22.10[2824,-1596]$ & 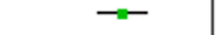 & & \\
\hline Muicooli 2006 & 40 & 6.8 & 50 & 46.7 & 10.8 & 50 & $22.5 x$ & $-6.70[-10.24,-3.16]$ & - & & \\
\hline Ortega 2004 & 86 & 20 & 57 & 101 & 16 & 57 & $20.4 x$ & $-15.00[-21.65,-8.35]$ & -- & & \\
\hline Pap avramidis 2009 & 76.67 & 22.88 & 45 & 101.74 & 20.76 & 45 & $18.3 x$ & $-25.07[34.10,-1604]$ & & & \\
\hline Tdal (95\% Cl) & & & 303 & & & 305 & $1000 \%$ & $-18.74[-2697,-1052]$ & & & \\
\hline \multicolumn{7}{|c|}{$\begin{array}{l}\text { Heterogeneity: } \text { Tau }^{x}=7482 ; \mathrm{Chi}^{x}=31.77, \mathrm{df}=5(\mathrm{P}<000001) ; I^{x}=84 \mathrm{x} \\
\text { Test broverall effe } \mathrm{d}: Z=4.47(\mathrm{P}<0.00001)\end{array}$} & & & $\begin{array}{lcc}-50 & -25 & 0 \\
\text { Favours UAS }\end{array}$ & $\begin{array}{c}25 \\
\text { Favours } \mathrm{CT}\end{array}$ & $\overrightarrow{50}$ \\
\hline
\end{tabular}

Figure 1 Meta-analysis of operative duration $(\mathrm{min})$ in total thyroidectomy with ultrasonic dissector of the first generation versus conventional clamp and tie. 


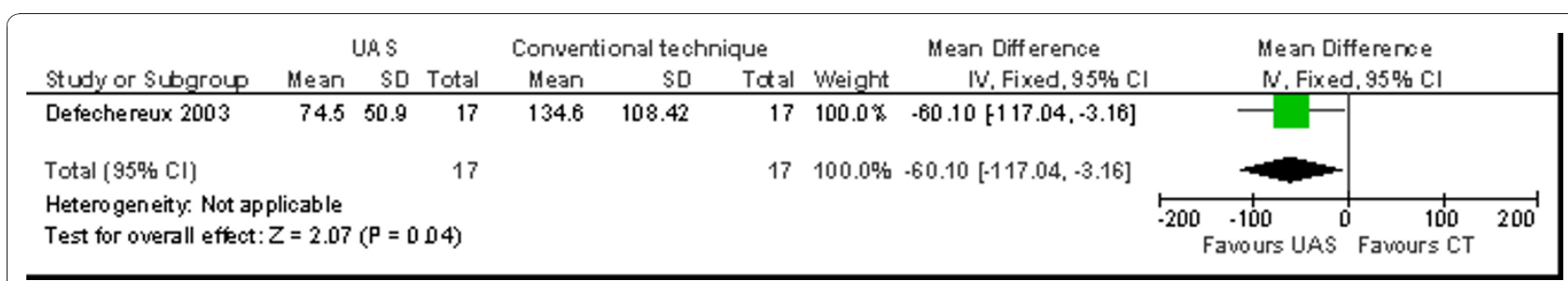

Figure 2 Meta-analysis of operative blood loss $(\mathrm{ml})$ in total thyroidectomy with ultrasonic dissector of the first generation versus conventional clamp and tie.

\begin{tabular}{|c|c|c|c|c|c|c|c|c|c|c|c|}
\hline \multirow[b]{2}{*}{ Study or Subgroup } & \multicolumn{3}{|c|}{ UA S } & \multicolumn{3}{|c|}{ Conventional te chnique } & \multicolumn{2}{|r|}{ Mean Difference } & \multirow{2}{*}{\multicolumn{3}{|c|}{$\begin{array}{l}\text { Mean Difference } \\
\mathrm{N} \text {, Fixed, } 95 \% \mathrm{Cl}\end{array}$}} \\
\hline & Mean & $S D$ & Total & Mean & SD & Tdal & Weight & IV, Fixed, 95\% $\mathrm{Cl}$ & & & \\
\hline Miccoli 2006 & 40.1 & 25.4 & 50 & 75.4 & 43.4 & 50 & $100.0 \%$ & $-35.30[-49.24,-21.36]$ & - & & \\
\hline Total $(95 \% \mathrm{Cl})$ & & & 50 & & & 50 & $100.0 \%$ & $-35.30[-4924,-21.36]$ & & & \\
\hline \multicolumn{4}{|c|}{$\begin{array}{l}\text { Heterogeneity: Not ap plicable } \\
\text { Test for overall effect: } Z=4.96 \text { ( } P<000001 \text { ) }\end{array}$} & & & & & & $-50 \begin{array}{cc}-25 & 0 \\
\text { Fawours UAS } & \end{array}$ & $\begin{array}{c}25 \\
\text { Fawours CT }\end{array}$ & 50 \\
\hline
\end{tabular}

Figure 3 Meta-analysis of overall drainage volume $(\mathrm{mL})$ in total thyroidectomy with ultrasonic dissector of the first generation versus conventional clamp and tie.

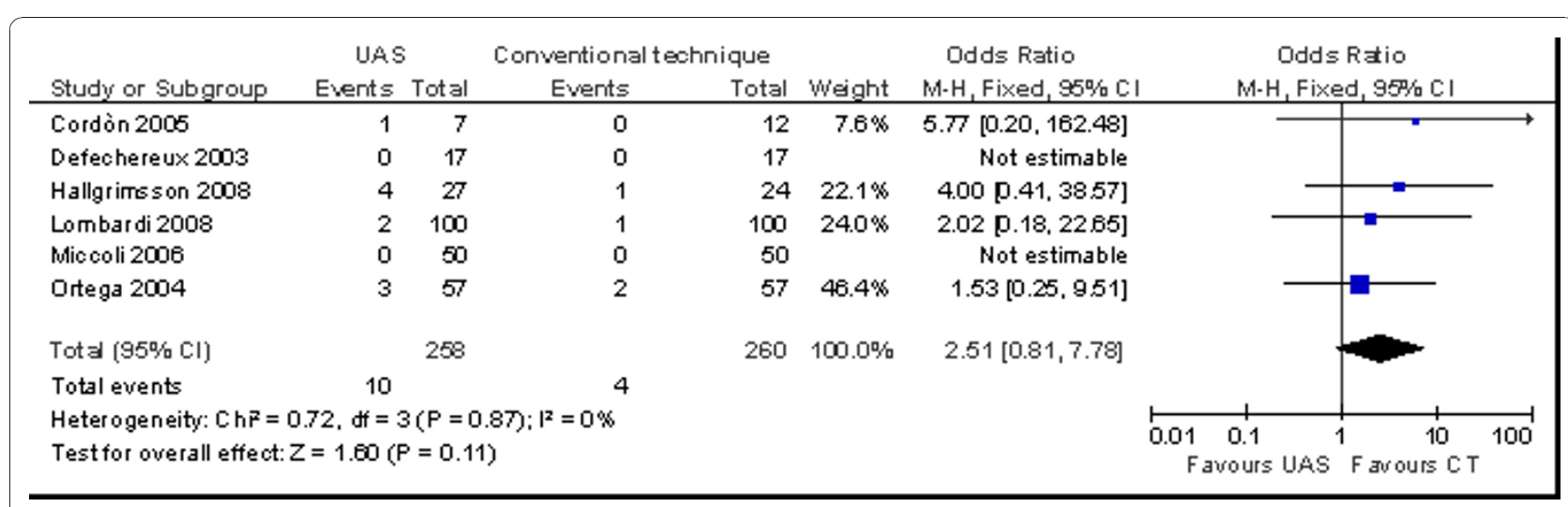

Figure 4 Meta-analysis of incidence of transiet nerve plasy (n. patients) in total thyroidectomy with ultrasonic dissector of the first generation versus conventional clamp and tie.

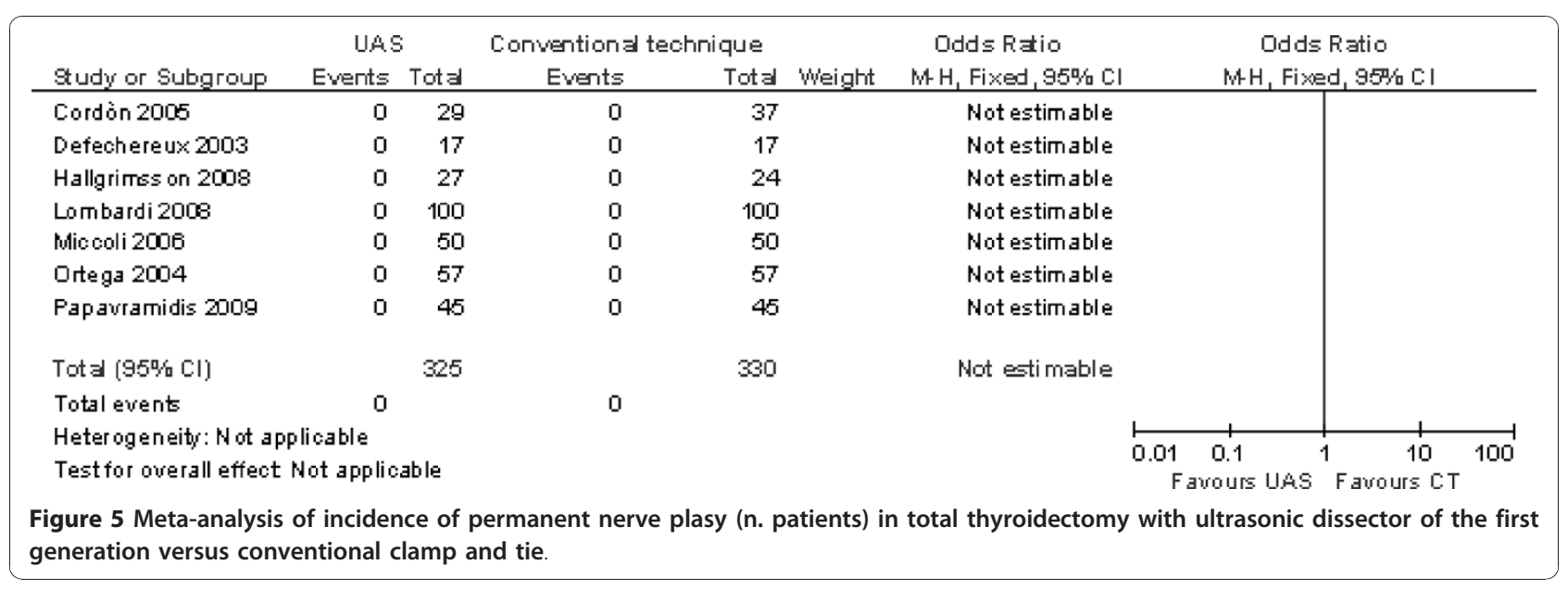




\begin{tabular}{|c|c|c|c|c|c|c|c|}
\hline \multirow[b]{2}{*}{ Study or Subgroup } & \multicolumn{2}{|l|}{ UAS } & \multicolumn{3}{|c|}{ Conventional technique } & \multirow{2}{*}{$\begin{array}{c}\text { Odds Ratio } \\
\mathrm{M} \cdot \mathrm{H} \text {, Fixed, } 95 \% \mathrm{Cl}\end{array}$} & \multirow{2}{*}{$\begin{array}{c}\text { Odds Ratio } \\
\mathrm{M} \cdot \mathrm{H} \text {, Fixed, } 95 \% \mathrm{Cl}\end{array}$} \\
\hline & Events & Total & Events & Total & Weight & & \\
\hline Cordòn 2005 & 3 & 7 & 9 & 12 & $9.3 \%$ & $0.25[0.03,182]$ & - \\
\hline Defechereu $\times 2003$ & 1 & 17 & 4 & 17 & $9.3 \%$ & $0.20[0.02,205]$ & \\
\hline Hallgrims son 2008 & 8 & 27 & 9 & 24 & $16.5 \%$ & $0.70[0.22,226]$ & \\
\hline Lombardi 2008 & 28 & 100 & 29 & 100 & $51.4 \%$ & $0.95[0.52,1.76]$ & \\
\hline Mic coli 2006 & 0 & 50 & 0 & 50 & & Not estimable & \\
\hline Ortega 2004 & 5 & 57 & 6 & 57 & $13.5 \%$ & $0.82[0.23,285]$ & 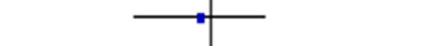 \\
\hline Tot $=(95 \% \mathrm{Cl})$ & & 258 & & 260 & $100.0 \%$ & $0.76[0.48,1.21]$ & \\
\hline Total events & 45 & & 57 & & & & \\
\hline \multicolumn{7}{|c|}{ Heter ogeneity: $C h \vec{F}=301, d f=4(P=0.56):\left.\right|^{2}=0 \%$} & 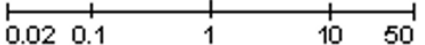 \\
\hline \multicolumn{7}{|c|}{ Test for overall effect: $Z=1.17(P=0.24)$} & Favours UAS F avours CT \\
\hline
\end{tabular}

Figure 6 Meta-analysis of incidence of transient hypocalcaemia (n. patients) in total thyroidectomy with ultrasonic dissector of the first generation versus conventional clamp and tie.

The hypocalcaemia is subsequent to parathyroid glands damage during thyroidectomy. The transient hypocalcaemia appears in $10 \%$ of total thyroidectomies, permanent in 1\% [13-19]. The transient hypocalcaemia could be also severe and needs to be treated with iv or oral therapy. The permanent hypocalcaemia requests a long-life treatment with calcium supplements and vitamin $\mathrm{D}$ analogues. The long-life treatment with supplements could have some inconveniences like osteomalacia. The incidence of parathyroid glands damage could be reduced only performing a precise surgical techniques to preserve blood supply.

In the most cases, laryngeal nerve palsy is not frequent and transient (10\% after total thyroidectomy) and can be resolved spontaneously maximum in one month [13-19]; permanent paralysis is very rare (1\%) and need a complex treatment (vocal cord injection or laryngoplasty) [13-19].

The prevention of those lesions is of high importance and can be obtained only with an accurate dissection.
The experience and choice of surgical techniques represent the unique cause of hypocalcaemia and laryngeal nerve palsy, Kocher evidenced this problem: "Since we have adhered strictly to this procedure, the hoarseness, formerly so frequently observed after operation, has now become exceptional". Recently a new UAS handpiece was commercialized (Harmonic Focus) with a tip smaller than $5 \mathrm{~mm}$. These smaller tips should permit more precise and accurate dissection with a subsequent reduction of post operative complications.

Actually, it was shown from this meta-analysis of the seven randomized clinical trials (RCT) a relevant advantage only in terms of cost-effectiveness (reduction of operating room utilization and recovering) in patients treated with UAS (first generation "Harmonic scalpel"; Johnson \& Johnson ${ }^{\circledR}$ ), it is subsequent to statistically significant reduction of operation duration ( $p=$ $0.00001)$, intraoperative blood loss $(p=0.04)$ and of overall drainage volume during the first 24 hours $(p=$ 0.00001). Although the analysis showed that the patients

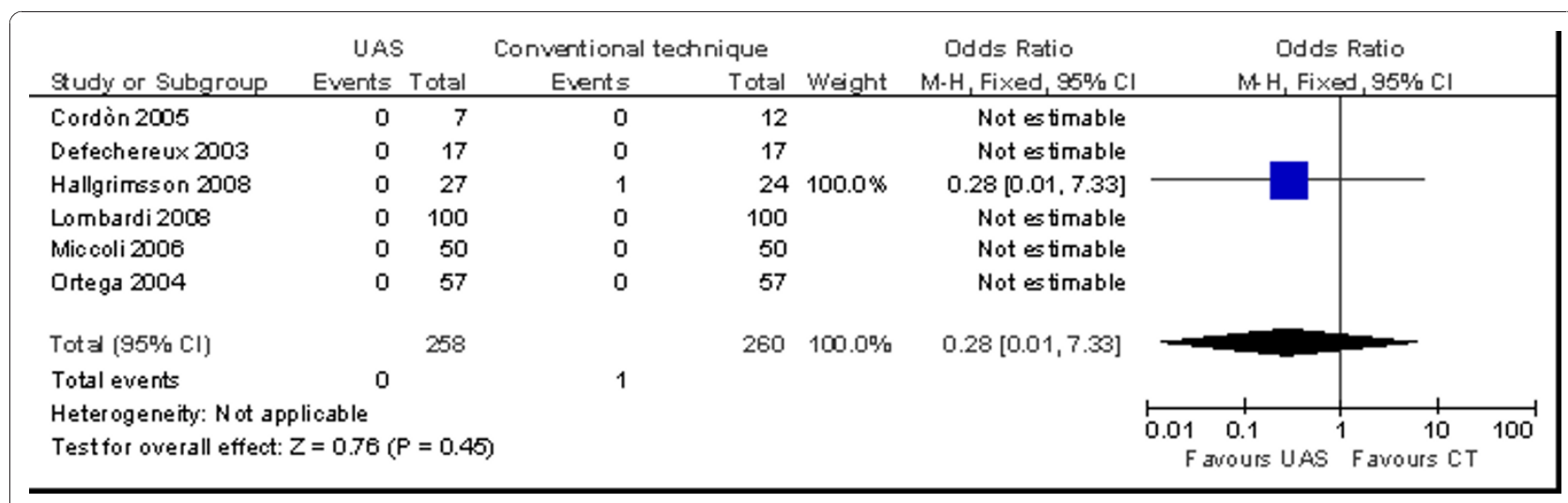

Figure 7 Meta-analysis of incidence of permanent hypocalcaemia (n. patients) in total thyroidectomy with ultrasonic dissector of the first generation versus conventional clamp and tie. 
who were treated with Ultrasonic dissector presented more favourable results in incidence of post-operative complications (transient laryngeal nerve palsy: $p=0.11$; permanent laryngeal nerve palsy: not estimable; transient hypocalcaemia: $p=0.24$; permanent hypocalcaemia: $p=$ 0.45 ), these data didn't present statistical relevance.

The experience of surgeon is the only significant factor of appearance of complications, utilization of Ultrasonic dissector can only facilitate surgical procedure, but can not substitute the experience of surgeon.

It's necessary to do new and more enlarged RCT with new UAS Focus, this should permit a more correct evaluation of advantages of UAS in reduction of post operative complications.

\section{Author details}

${ }^{1}$ General and Emergency Surgical Unit. Department of Surgical Sciences, Radiology and Dentistry. University of Perugia, Perugia, Italy. ${ }^{2}$ Endocrine Surgical Unit. Department of Surgical Sciences, Radiology and Dentistry. University of Perugia, Perugia, Italy. ${ }^{3}$ Department of Surgical Sciences. Sapienza University of Rome, Rome, Italy. ${ }^{4}$ Public Health Department. University of Perugia, Perugia, Italy. ${ }^{5}$ Department Paride Stefanini. Sapienza University of Rome, Rome, Italy.

\section{Authors' contributions}

RC, FD, ST: Literature search and identification of trials, writing the text of review. AS, GR, DV: Evaluation of methodological quality of trials, data collection. RL, DG, AS: Literature search and identification of trials. $F S, A B, A N$ : Revision of the review.

All authors read and approved the final manuscript.

\section{Competing interests}

The authors declare that they have no competing interests.

Received: 8 September 2010 Accepted: 23 December 2010 Published: 23 December 2010

\section{References}

1. Ellis $\mathrm{H}$ : Thyroid and parathyroid. The Cambridge illustrated history of surgery, Cambridge University Press, Cambridge; 2009, 195-209.

2. Iacconi P, Bendinelli C, Miccoli P: Endoscopic thyroid and parathyroid surgery. Surg Endosc 1999, 13:314-5.

3. Kirdak T, Korun N, Ozguc H: Use of ligasure in thyroidectomy procedures: results of a prospective comparative study. World I Surg 2005, 29(6):771-4.

4. Defechereux T, Rinken F, Maweja $\mathrm{S}$, et al: Evaluation of the ultrasonic dissector in thyroid surgery. A prospective randomised study. Acta Chir Belg 2003, 103:274-7.

5. Ortega J, Sala C, Flor B, et al: Efficacy and cost-effectiveness of the UltraCision harmonic scalpel in thyroid surgery: an analysis of 200 cases in a randomized trial. J Laparoendosc Adv Surg Tech A 2004, 14:9-12.

6. Cordón C, Fajardo R, Ramírez J, et al: A randomized, prospective, parallel group study comparing the Harmonic Scalpel to electrocautery in thyroidectomy. Surgery 2005, 137:337-41.

7. Miccoli P, Berti P, Dionigi G, et al: Randomized controlled trial of harmonic scalpel use during thyroidectomy. Arch Otolaryngol Head Neck Surg 2006, 132:1069-73.

8. Hallgrimsson P, Lovén L, Westerdahl J, et al: Use of the harmonic scalpel versus conventional haemostatic techniques in patients with Grave disease undergoing total thyroidectomy: a prospective randomised controlled trial. Langenbecks Arch Surg 2008, 393:675-80

9. Lombardi CP, Raffaelli M, Cicchetti A, et al: The use of "harmonic scalpel" versus "knot tying" for conventional "open" thyroidectomy: results of a prospective randomized study. Langenbecks Arch Surg 2008, 393:627-31.
10. Papavramidis TS, Sapalidis K, Michalopoulos N, et al: Ultracision harmonic scalpel versus clamp-and-tie total thyroidectomy: A clinical trial. Head Neck 2009, 29.

11. Voutilainen $\mathrm{PE}$, Haglund $\mathrm{CH}$ : Ultrasonically activated shears in thyroidectomies: a randomized trial. Ann Surg 2000, 231:322-8

12. Yao HS, Wang Q, Wang WJ, et al: Prospective clinical trials of thyroidectomy with LigaSure vs conventional vessel ligation: a systematic review and meta-analysis. Arch Surg 2009, 144:1167-74.

13. Thompson NW, Nishiyama RH, Harness JK: Thyroid carcinoma: current controversies. Curr Prob/ Surg 1978, 15:1-67.

14. Farrar WB, Cooperman M, James AG: Surgical management of papillary and follicular carcinoma of the thyroid. Ann Surg 1980, 192:701-4.

15. Schroder DM, Chambors A, France CJ: Operative strategy for thyroid cancer. Is total thyroidectomy worth the price? Cancer 1986, 58:2320-8.

16. Clark $\mathrm{OH}$ : Total thyroidectomy: the preferred option for multinodular goiter. Ann Surg 1988, 208:244-5

17. Ley PB, Roberts JW, Symmonds RE Jr, et al: Safety and efficacy of total thyroidectomy for differentiated thyroid carcinoma: a 20-year review. Am Surg 1993, 59:110-4.

18. Tartaglia F, Sgueglia M, Muhaya A, et al: Complications in total thyroidectomy: our experience and a number of considerations. Chir Ital 2003, 55:499-510.

19. Rosato L, Avenia N, Bernante $P$, et al: Complications of thyroid surgery: analysis of a multicentric study on 14,934 patients operated on in Italy over 5 years. World J Surg 2004, 28:271-6.

doi:10.1186/1477-7819-8-112

Cite this article as: Cirocchi et al:: Meta-analysis of thyroidectomy with ultrasonic dissector versus conventional clamp and tie. World Journal of Surgical Oncology 2010 8:112.

\section{Submit your next manuscript to BioMed Central and take full advantage of:}

- Convenient online submission

- Thorough peer review

- No space constraints or color figure charges

- Immediate publication on acceptance

- Inclusion in PubMed, CAS, Scopus and Google Scholar

- Research which is freely available for redistribution

Submit your manuscript at www.biomedcentral.com/submit 